\title{
STUDY OF ATTITUDE AND PERCEPTION OF MEDICAL STUDENTS REGARDING THE MEDICAL CURRICULUM AND SYLLABUS IN A TEACHING MEDICAL COLLEGE OF EASTERN INDIA
}

\author{
BandyopadhyayDebasis
}

DrDebasisBandyopadhyay, Associate professor, Department of Pharmacology, Burdwan Medical College, West Bengal, India-713104

*Corresponding Author's Email: drdebasisbandyopadhyay@yahoo.in, Mobile No.09474786492

\begin{abstract}
Background: Recently there is emphasize on better development of skill, behaviors, and attitudes of medical students, the future doctors, in all part of the world. For that well-constructed medical curriculum cum syllabus is essential. There is rapid change of disease pattern and change of social demand from the doctors, need the change of medical curriculum and syllabus. It necessitates the good planning of the change of curriculum and syllabus. Good feedback from the medical students regarding the attitude and perception of current curriculum and syllabus can only improve the quality of the planning and subsequent change. Lots of studies conducted on this area in different part of the world, yielding varying results. In this perspective there was need for further studies, especially in this part of the world, Burdwan Medical College, West Bengal, India, where there was no such studies conducted before.Objective: The objective of my study was to assess the attitude and perception of the medical students regarding the present medical curriculum and syllabus with emphasis on the gender difference if any. Materials and Methods: Pre validated, Reliable, standardized, predesigned 11 points based structured questionnaires were distributed among randomly recruited 90 medical students of final M.B.B.S. of 2007-2008 batch, during the $3^{\text {rd }}$ week of the January 2012. The response of the questionnaires was assessed in the five point Likert scale.Results: Out of the $93.33 \%$ responder, male was $91.379 \%$ \& female was $96.875 \% .73 .56 \%$ female students \& $78.50 \%$ male students disagreed, including strongly disagreed that their problem solving skill were being developed by this syllabus. $73.58 \%$ of female students \& $81.48 \%$ of male students disagreed, including strongly disagreed that the enjoyment outweighs the stress of the syllabus. Whereas more than $80 \%$ of both female \& male students agreed, including strongly agreed regarding the adequacy of the current time span within the syllabus. But more than $87 \%$ of both male \& female students agreed, including strongly agreed regarding the need of change of medical curriculum \& syllabus, with more focused towards on the problem based learning ( PBL). Conclusion: Though the study conducted in one institution \& in one academic year, but majority of the both male and female medical students of this institution gave their favoring opinion regarding the change of medical curriculum\& syllabus, focused more on PBL.
\end{abstract}

Key words: Medical, Curriculum, Syllabus, Attitude, Perception.

\section{INTRODUCTION}

Prideaux David stated ${ }^{1}$ that the curriculum represents the expression of educational ideas in practice. The word curriculum has its roots in the Latin word for track or race course. From there it came to mean course of study or syllabus. Today the definition is much wider and includes all the planned learning experiences of a school or educational institution ${ }^{1}$. Both syllabus and curriculum are often fused; a syllabus usually contains specific information about the course, an outline of what will be covered in the course ${ }^{2,3}$. Stenhouse L stated that a curriculum is an attempt to communicate the essential principles and features of an educational proposal in such a form that it is open to critical scrutiny and capable of effective translation into practice ${ }^{4}$ and any reform in the curriculum should respond to current problems and future demands ${ }^{5}$. Recently WHO has taken the strategy to reform the curriculum in to more community oriented several newer concepts such as community oriented medical education and problem based/ oriented learning, integrated medical education and learner-centered educational activity, others include the emergence of newer education methods particularly professional and clinical skill ${ }^{6,7}$.

A curriculum may also refer to a defined and prescribed course of studies, which students must fulfill in order to pass a certain level of education ${ }^{8}$. A critical look at the medical curriculum in different countries reveals gross inadequacies which are directly and amply reflected in their products i.e. doctors. The deficiencies are (C) 2011, JDDT. All Rights Reserved multidimensional and include character, capabilities, care, commitment and performance. Jungle of useless details of the curriculum masks the essentials and kills the creativity of the students. The poorly trained and defectively formed doctors spoil the systems. All these contribute towards overall failed and incompetent health systems ${ }^{9}$.

With recent changes in the evidence base of medical education and health service delivery, it is time to examine the very core and infrastructure of the medical curriculum. This will ensure that the programme continues to produce the next generation of doctors with appropriate knowledge, skills and professional attitudes in keeping with the challenges of modern medical practice ${ }^{10}$. Enhancing the student experience is a key theme of the medical education, providing students with a high quality experience that is distinctive in the higher education sector. Curriculum review enables a re-evaluation of the student learning journey including the procedures and systems involved in planning and delivering programmes of study 11. And for these students feedback for attitude\& perception regarding the present medical curriculum and syllabus is essential. Students' perception and feedback is the driver for the good planning and subsequent curriculum reform. Different countries in the world are engaged in the studies on this area, yielding varying results $12,13,14,15,16$. In this scenario there was a demand of such a study especially at this part of the world, Burdwan Medical College, West Bengal,India, where in the past there was no ISSN: 2250-1177

CODEN (USA): JDDTAO 
such study conducted. In this background I conducted this study myself in my Institute.

\section{MATERIALS AND METHODS:}

Participants: In this study 90 medical students of final M.B.B.S. of 2007-2008 batch, were randomly recruited at the Burdwan Medical College, West Bengal, India.

Ethical consideration: This study was approved by the institutional ethical committee and valid written informed consent was taken from each students.

Study duration: The duration of the study was only three days, during the $3^{\text {rd }}$ week of 2012 .

Study design: My study was prospective, open level, unblinded, and uncontrolled study.

Methodology: Pre validated, Reliable, standardized, predesigned 11 points based structured questionnaires (Table No. 1)were distributed among the randomly recruited 90 medical students. The students were asked to answer the questionnaires in unbiased\& truthful way and not to produce their identity on the questionnaires. All the questionnaires were approved by my institutional ethical committee.

Validity: Validity of the questionnaires was assessed by the Pearson-r coefficient.Validityis a complicated concept in testing. An examination is valid when it measures what it supposed to measure. This is not a yes or none law response answer but the degree to which supporting evidence has been produced, or to what degree a theoretical aspect supports an interpretation ${ }^{17}$.
Reliability: Reliability of the questionnaires was assessed by the Cronbach's Alpha Reliability Coefficient for Likert-type Scales Reliability is a concept of statistic; it is the degree to which a test consistently measures. In this study reliability and validity coefficient of my eleven points based questionnaires were 0.79 and 0.84 respectively.

Outcome measurement: Five point Likert response scale was used as outcome measurement as $0=$ strongly disagree; 4= strongly agree. Likert Scale $^{18}$, a psychometric response scale primarily used in questionnaires to obtain participants preferences or degree of agreement with a statement or set of statements. Likert scales are a non-comparative scaling technique and are uni-dimensional (only measure a single trait) in nature. Respondents asked to indicate their level of agreement with a given statement by way of an ordinal scale. Likert scale is a responder scale. Likert Scale named after the name of Dr RensisLikert. He was a sociologist at the University of Michigan and developed the technique for the measurement of attitude, and it was published in the archives of psychology in $1932^{19}$.

Statistical analysis: All the collected data were analyzed with the descriptive statistics by using the Statistical Package for the Social Science (SPSS) ver-16 in Windows-7. The independent Simple t-test was applied to detect any significant difference of perception between the responses of different questionnaires. A value of $\mathrm{p}<0.05$ was considered statistically significant. But frequency analysis and content analysis of the responders, done by manually.

Table No. 1: Showing reliable, validated, standardized, attitude and perception based 11 point questionnaires regarding the medical curriculum\& syllabus.

\begin{tabular}{|l|l|}
\hline Question No. & \multicolumn{1}{|c|}{ Type of Questionnaires } \\
\hline Question No. 1 & I am too tired to enjoy the curriculum \\
\hline Question No. 2 & My problem solving skill are being developed by this curriculum \\
\hline Question No. 3 & The enjoyment in the syllabus outweigh the stress of the course \\
\hline Question No. 4 & Much of what I have to learn in the current syllabus seems relevant to a career. \\
\hline Question No. 5 & This syllabus emphasize the long term learning than short term learning \\
\hline Question No. 6 & I am clear about the learning objectives of the course \\
\hline Question No. 7 & I am really bored \& stressed by this curriculum \\
\hline Question No.8 & Current time span in the curriculum is adequate \\
\hline Question No.9 & The syllabus should be provided to the students at the beginning of the of the academic year \\
\hline Question No. 10 & Present curriculum stimulate the research activity among the students \\
\hline Question No. 11 & $\begin{array}{l}\text { Need change of curriculum more focused on Problem Based Learning(P.B.L.)\& evidence based } \\
\text { learning }\end{array}$ \\
\hline
\end{tabular}

\section{RESULTS AND ANALYSIS:}

In my study, total 90 medical students of final M.B.B.S. of batch 2007-2008, were recruited randomly. Male was 58 $(64.444 \%)$ and Female was $32(35.555 \%)$. Mean age was $21 \pm 0.8$ years for the male and $21 \pm 0.4$ years for the female students. The 11 point based questionnaires were distributed among the recruited students. 84 students $(93.33 \%)$ responded. Out of that 53 students $(91.379 \%)$ were Male and 31students $(96.875 \%)$ were Female. Out of the total female was $51 \%$ and male was $49 \%$.

In the Figure No. 1, it shows that female student responded more than that of the male students. The details of the responses, in the five point Likert Scale, among both Male and Female Final Year M.B.B.S. students of 2007-2008 batch, of Burdwan Medical College, West Bengal, India, are distributed in Table No 2 \& 3 and in Figure No 2 \&3. 
Figure 1: Showing the responder rate among the Male and Female Medical Students:

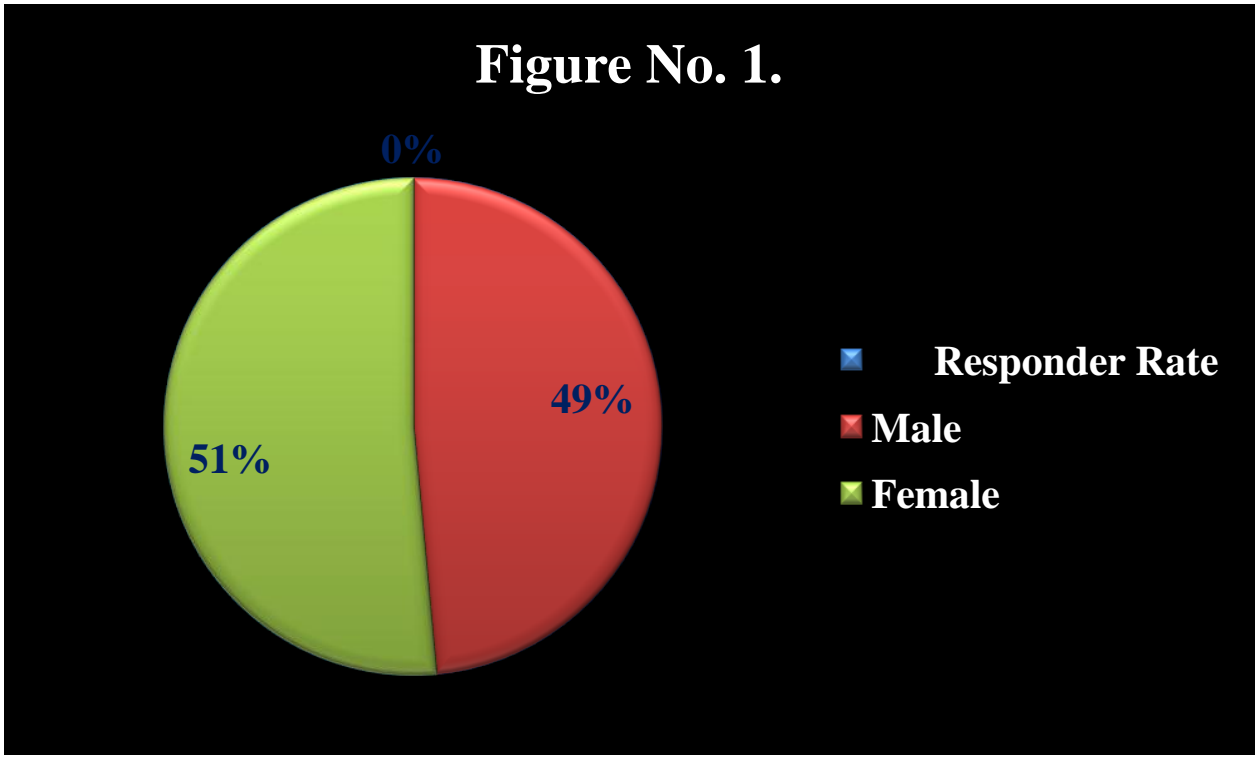

Table No. 2: Showing the details responses of the questionnaires 1-5, in the five point Likert response scale, among Male and Female Final M.B.B.S Medical Student of Burdwan Medical College.

\begin{tabular}{|l|l|l|l|l|l|l|l|l|l|l|}
\hline Tabl. No. 2 & Strongly Disagree & \multicolumn{2}{|c|}{ Disagree } & \multicolumn{2}{|c|}{ Do not know } & \multicolumn{2}{c|}{ Agree } & \multicolumn{2}{c|}{ Strongly Agree } \\
\hline Question No. & Female & Male & Female & Male & Female & Male & Female & Male & Female & Male \\
\hline Question No. 1 & $\mathbf{3 . 4 1 \%}$ & $\mathbf{3 . 2 1 \%}$ & $\mathbf{3 . 5 0 \%}$ & $\mathbf{2 . 9 9 \%}$ & $\mathbf{2 . 1 1 \%}$ & $\mathbf{1 . 3 1 \%}$ & $\mathbf{5 5 . 0 9 \%}$ & $\mathbf{4 5 . 0 9 \%}$ & $\mathbf{3 5 . 8 9 \%}$ & $\mathbf{4 7 . 4 0 \%}$ \\
\hline Question No. 2 & $\mathbf{3 5 . 2 3 \%}$ & $\mathbf{3 8 . 2 1 \%}$ & $\mathbf{3 8 . 3 3 \%}$ & $\mathbf{4 0 . 2 9 \%}$ & $\mathbf{2 . 1 9 \%}$ & $\mathbf{2 . 1 3 \%}$ & $\mathbf{1 8 . 2 1 \%}$ & $\mathbf{8 . 0 9 \%}$ & $\mathbf{6 . 0 4 \%}$ & $\mathbf{1 1 . 2 8 \%}$ \\
\hline Question No. 3 & $\mathbf{3 6 . 3 9 \%}$ & $\mathbf{3 9 . 1 9 \%}$ & $\mathbf{3 7 . 1 9 \%}$ & $\mathbf{4 2 . 2 9 \%}$ & $\mathbf{3 . 0 3 \%}$ & $\mathbf{2 . 0 1 \%}$ & $\mathbf{1 2 . 2 2 \%}$ & $\mathbf{1 0 . 0 1 \%}$ & $\mathbf{1 1 . 0 7 \%}$ & $\mathbf{6 . 5 0 \%}$ \\
\hline Question No. 4 & $\mathbf{1 5 . 0 9 \%}$ & $\mathbf{1 8 . 1 1 \%}$ & $\mathbf{1 8 . 1 5 \%}$ & $\mathbf{1 9 . 2 9 \%}$ & $\mathbf{2 . 0 3 \%}$ & $\mathbf{2 . 1 1 \%}$ & $\mathbf{3 3 . 0 9 \%}$ & $\mathbf{3 1 . 2 6 \%}$ & $\mathbf{3 1 . 6 4 \%}$ & $\mathbf{2 9 . 2 3 \%}$ \\
\hline Question No. 5 & $\mathbf{3 2 . 1 9 \%}$ & $\mathbf{3 4 . 3 6 \%}$ & $\mathbf{3 3 . 1 1 \%}$ & $\mathbf{3 6 . 1 4 \%}$ & $\mathbf{4 . 1 9 \%}$ & $\mathbf{5 . 5 7 \%}$ & $\mathbf{1 8 . 1 5 \%}$ & $\mathbf{1 4 . 6 7 \%}$ & $\mathbf{1 2 . 3 6 \%}$ & $\mathbf{9 . 2 6 \%}$ \\
\hline
\end{tabular}

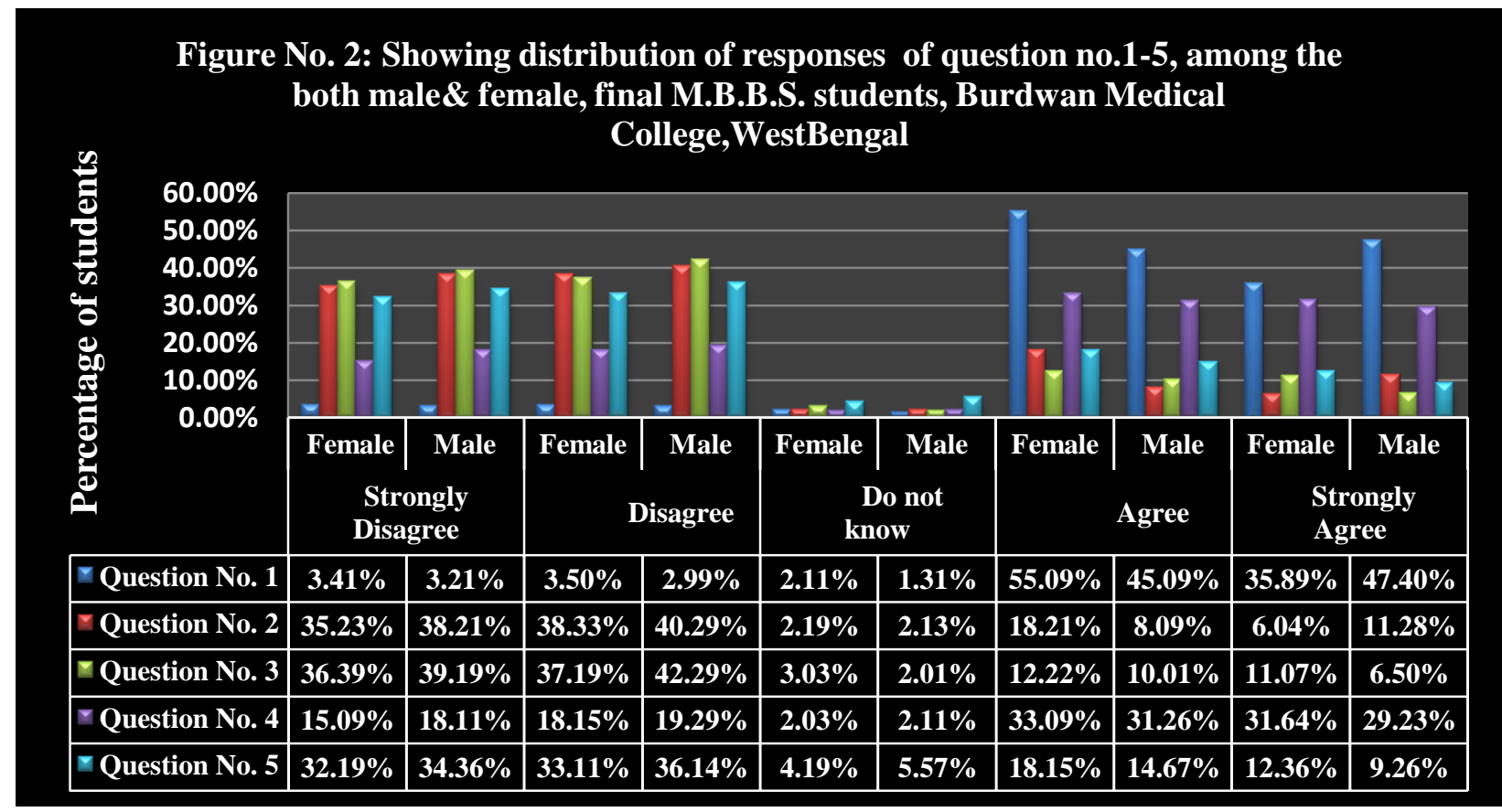

$90.98 \%$ of female students and $92.49 \%$ of male students agreed, including strongly agreed that they tired too much to enjoy the syllabus. $73.56 \%$ of female of final year medical students disagreed, including strongly disagreed that their problem solving skill being developed by this curriculum, whereas $78.50 \%$ of male final year medical students of the 2007-2008 batch strongly disagreed that. (C) 2011, JDDT. All Rights Reserved
$81.48 \%$ of male students disagreed, including strongly disagreed, that the enjoyments in the curriculum outweigh the stress; rather they felt more stress by the current curriculum. But $73.58 \%$ of female students disagreed, including strongly disagreed that. Whereas more than $60 \%$ of both male and female medical students agreed, including strongly agreed that whatever they have to learn ISSN: 2250-1177

CODEN (USA): JDDTAO 
in the current syllabus seems relevant to the career. In the following Figure No. 2, details distributions of the responses of both male \& female students are shown.

\begin{tabular}{|l|l|l|l|l|l|l|l|l|l|l|}
\hline Table No.3 & \multicolumn{2}{|l|}{ Strongly Disagree } & \multicolumn{2}{|c|}{ Disagree } & \multicolumn{2}{|c|}{ Do not Know } & \multicolumn{2}{c|}{ Agree } & \multicolumn{2}{l|}{ Strongly Agree } \\
\hline Question No & Female & Male & Female & Male & Female & Male & Female & Male & Female & Male \\
\hline Question No. 6 & $22.19 \%$ & $25.18 \%$ & $23.18 \%$ & $28.12 \%$ & $8.11 \%$ & $7.33 \%$ & $28.17 \%$ & $25.12 \%$ & $18.35 \%$ & $14.25 \%$ \\
\hline Question No. 7 & $3.33 \%$ & $2.13 \%$ & $3.73 \%$ & $2.91 \%$ & $1.19 \%$ & $1.89 \%$ & $60.13 \%$ & $55.00 \%$ & $31.62 \%$ & $38.07 \%$ \\
\hline Question No.8 & $5.09 \%$ & $7.06 \%$ & $6.17 \%$ & $9.18 \%$ & $2.11 \%$ & $3.09 \%$ & $50.09 \%$ & $48.01 \%$ & $36.54 \%$ & $32.66 \%$ \\
\hline Question No. 9 & $4.19 \%$ & $3.01 \%$ & $5.32 \%$ & $6.45 \%$ & $8.17 \%$ & $7.75 \%$ & $60.15 \%$ & $63.25 \%$ & $22.17 \%$ & $19.54 \%$ \\
\hline Question No. 10 & $39.15 \%$ & $41.55 \%$ & $41.05 \%$ & $43.65 \%$ & $3.09 \%$ & $3.19 \%$ & $8.01 \%$ & $7.78 \%$ & $8.70 \%$ & $3.83 \%$ \\
\hline Question No. 11 & $2.19 \%$ & $1.12 \%$ & $4.08 \%$ & $3.03 \%$ & $5.92 \%$ & $4.33 \%$ & $50.03 \%$ & $52.19 \%$ & $37.78 \%$ & $39.33 \%$ \\
\hline
\end{tabular}

In the above Table 3:Showing the details responses of the questionnaires 6-11, in the five point Likert response scale, among Male and Female Final M.B.B.S Medical Student of Burdwan Medical College.

Only $30.51 \%$ of female students agreed, including strongly agreed that the present curriculum emphasize the long term learning rather than short term learning. Whereas $23.93 \%$ of male students agreed that, including strongly agreed.In the following Figure No. 3, details distributions of the responses of questions no. 6-11, of both male \& female students are shown.

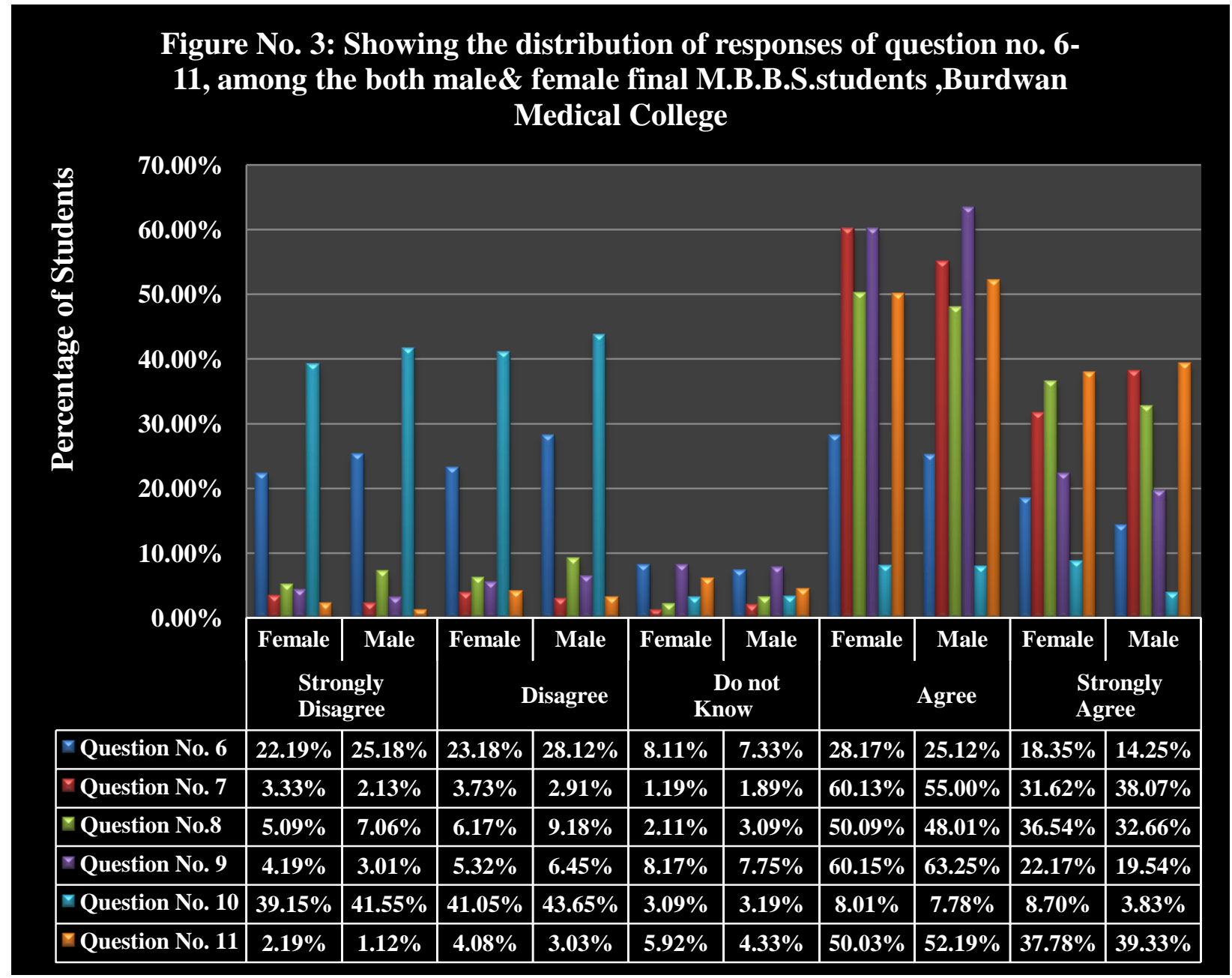

$46.52 \%$ of female students agreed, including strongly agreed that they were clear about the learning objective of the curriculum, whereas $39.37 \%$ of male students agreed, including strongly agreed that. In Figure No. 4,distribution of agreed responses, including strongly agreed responses among the Male Final Year Medical Students 2007-2008, of all the questionnaires are shown. 
Figure No.4:Showing Total Agreed Responses, including Strongly Agreed Responses among the Male Medical Students
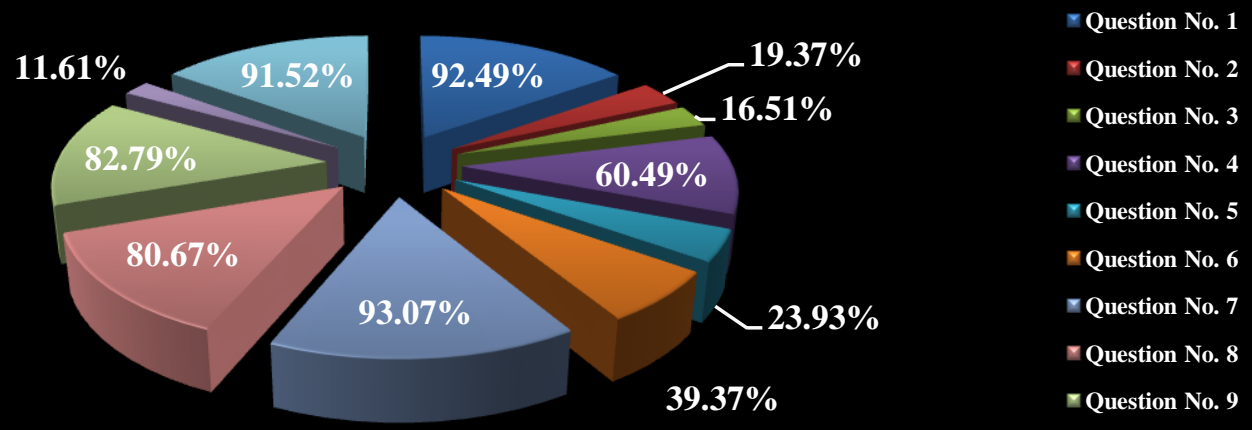

r Question No. 10

$91.75 \%$ of female students agreed, including strongly agreed that they really bored and stressed by the present curriculum, whereas $93.07 \%$ of male students agreed, including strongly agreed that. But $80.67 \%$ of male students agreed, including strongly agreed that the time span of the present curriculum adequate. Whereas $86.63 \%$ of female students agreed, including strongly agreed that. In Figure No.5distribution of agreed responses, including strongly agreed responses among the Female Medical Students, of all the questionnaires are shown.

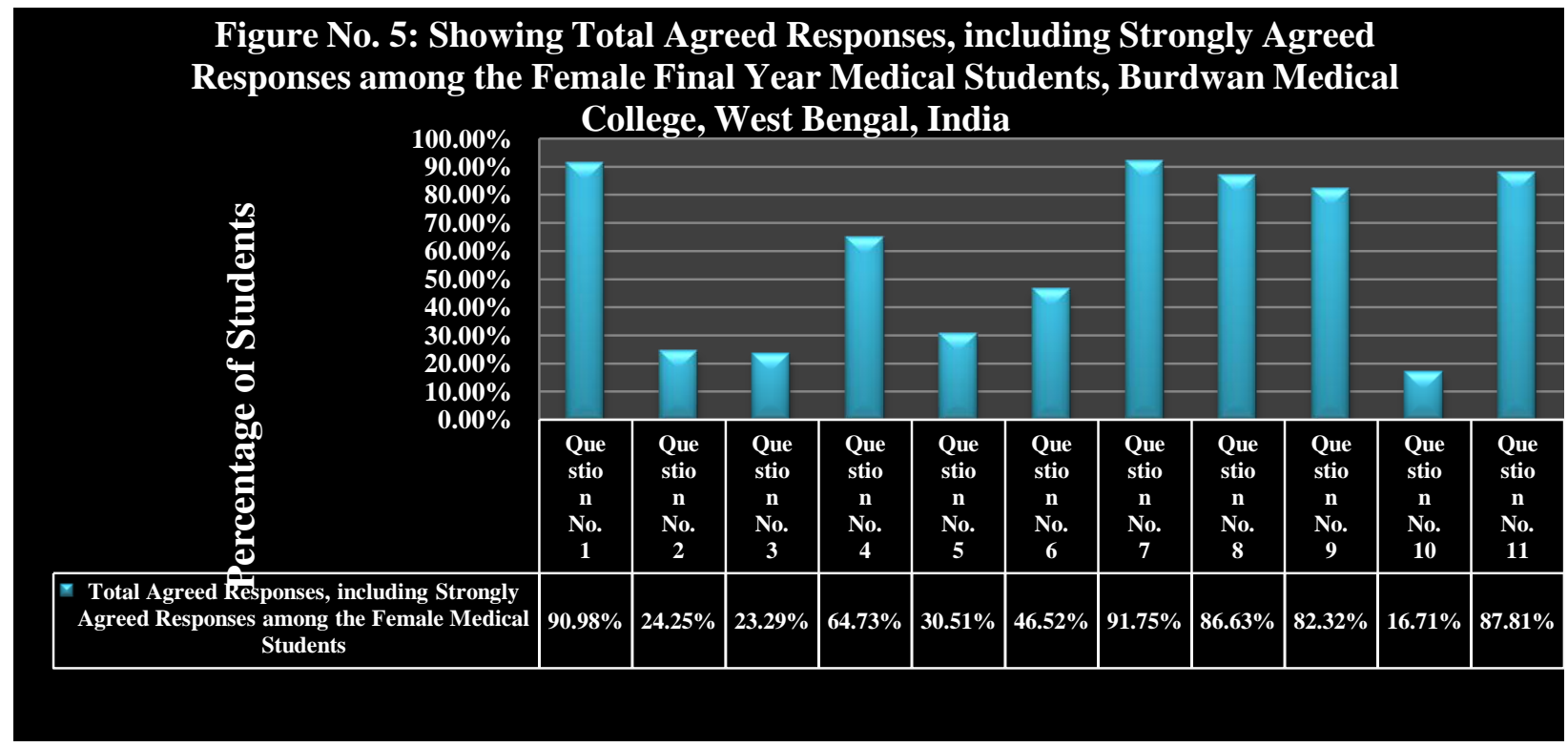

Figure No. 6: Showing Comparative Agreed Responses, including Strongly Agreed Responses, among both Male\& Female Final Year Medical Students, Burdwan Medical College, West Bengal, India

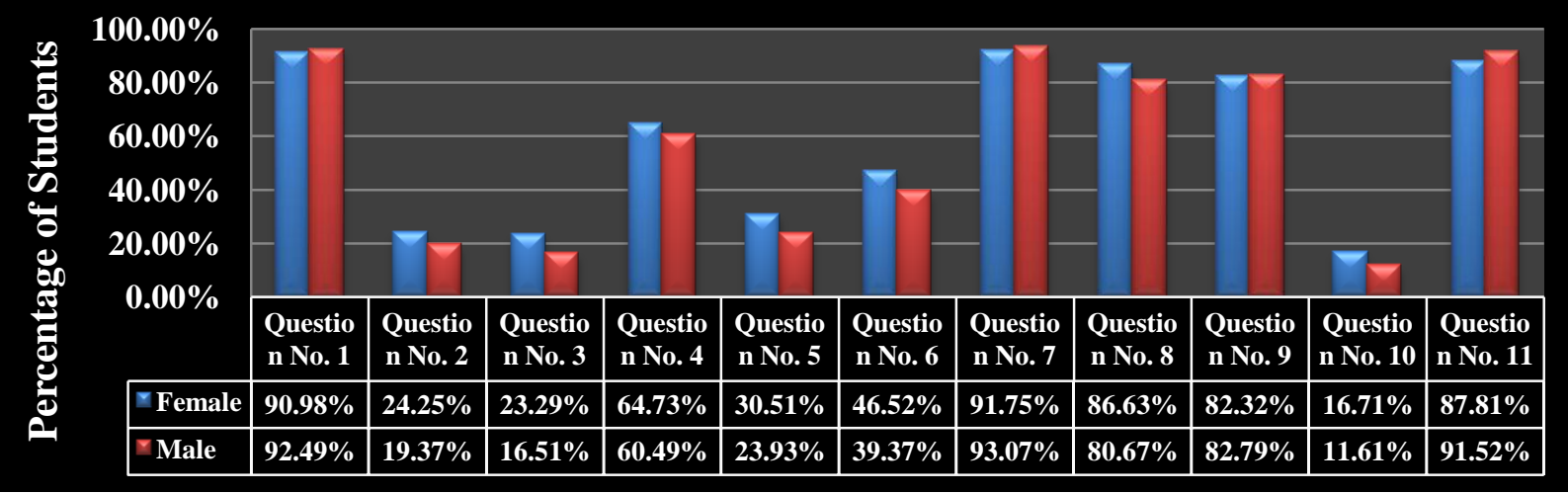


$82.32 \%$ of female students agreed, including strongly agreed that the syllabus should be provided to the students at the beginning of the academic year, $82.79 \%$ of male students also agreed, including strongly agreed that. Only $16.71 \%$ of female students agreed, including strongly agreed that present curriculum stimulate the research activity among the students, while only $11.61 \%$ of male students agreed that. More than $80 \%$ students of both male and female students rather disagreed that present curriculum stimulate the research activity among the students. In Figure No 6, comparative agreed responses, including strongly agreed responses among both male and female students are shown.

In Figure No. 7, distribution of disagreed responses, including strongly disagreed responses among the Male Final Year Medical Students 2007-2008, of all the questionnaires are shown.

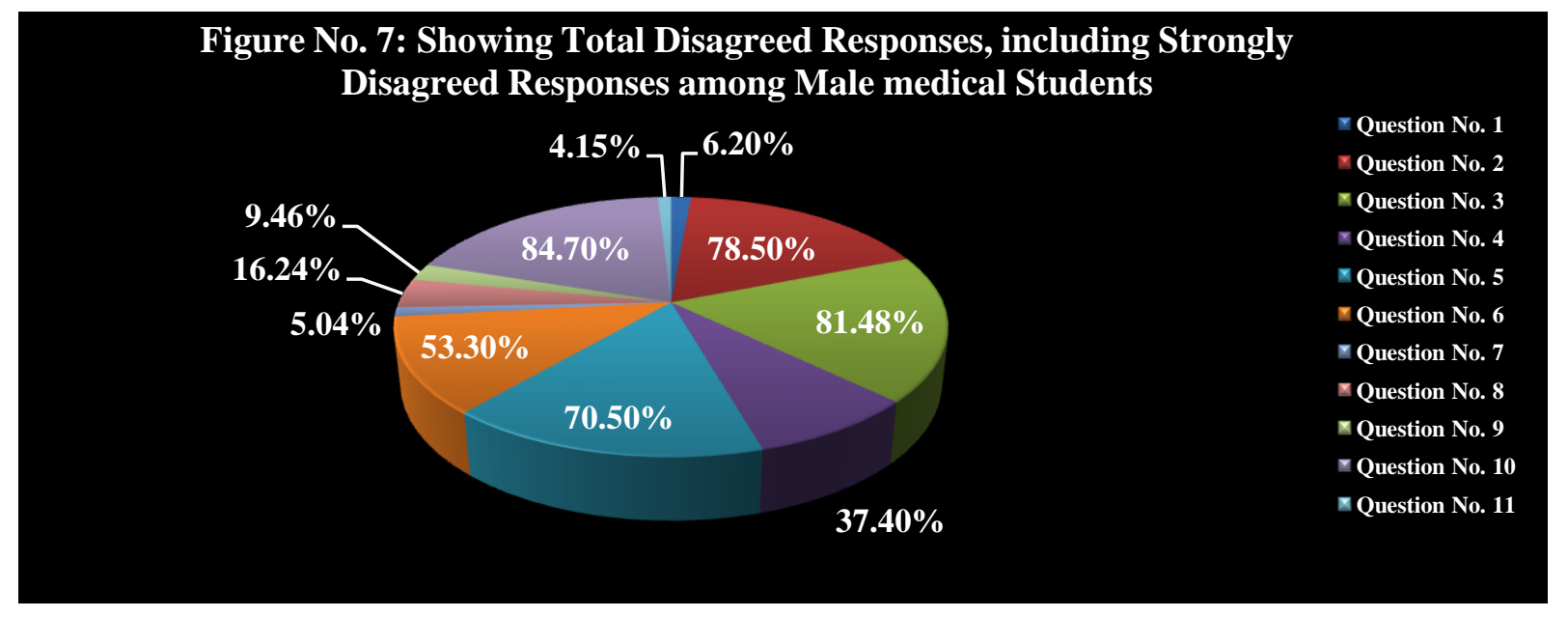

In Figure No.8distribution of disagreed responses, including strongly disagreed responses among the Female Medical Students, of all the questionnaires are shown.
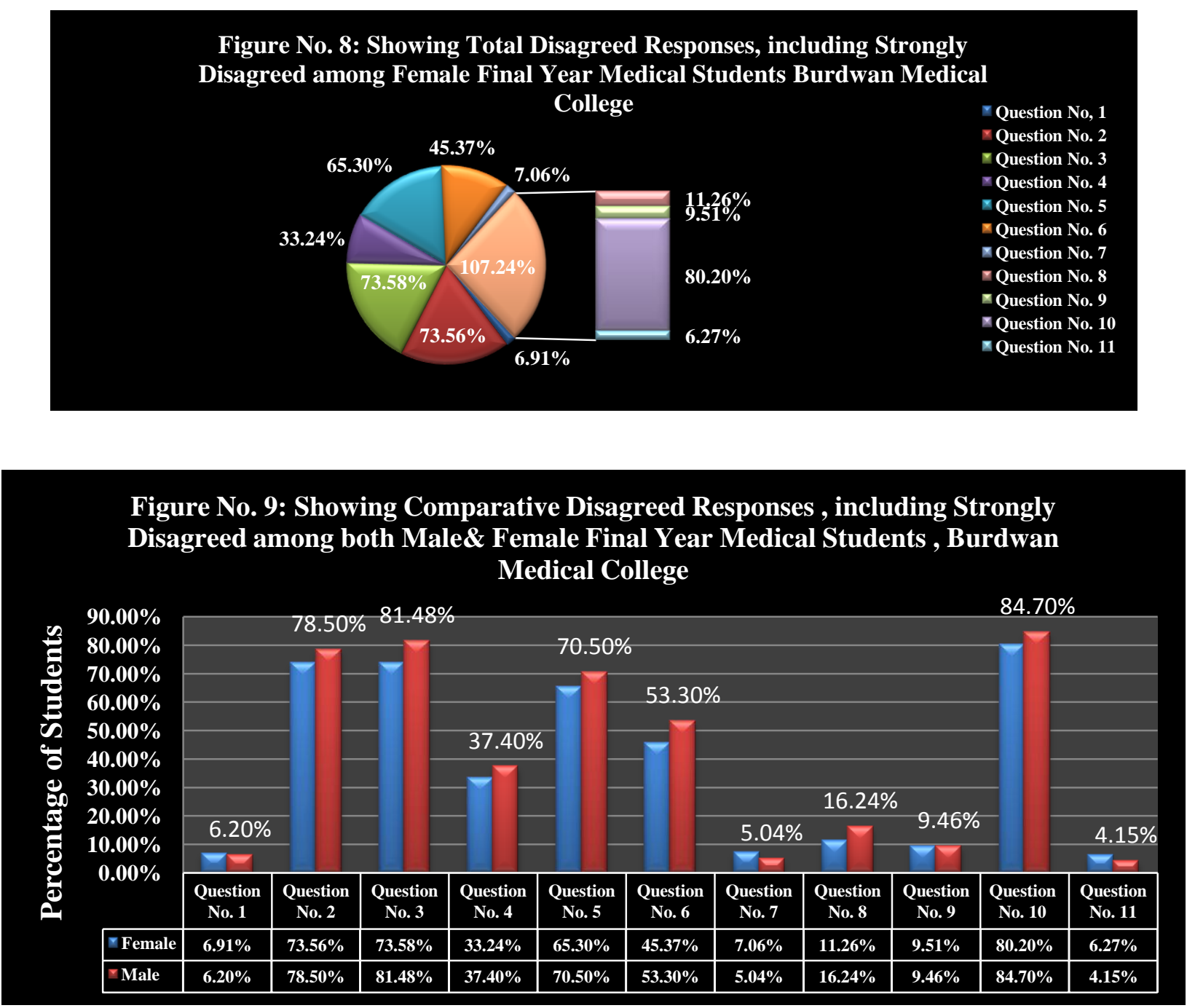
$87.81 \%$ of female students agreed, including strongly agreed that present curriculum should be changed, and $91.52 \%$ of male students agreed, including strongly agreed that. They gave their favorable opinion and more focused on the problem based learning and evidence based learning, as only $4 \%$ - $6 \%$ of both male and female students disagreed, including strongly disagreed that. In Figure No 9, comparative disagreed responses, including strongly disagreed responses among both male and female students are shown.

\begin{tabular}{|l|l|l|l|}
\hline Table No. 4 & Male Students( Mean \pm SD) & Female Students( Mean \pm SD) & $p$ value \\
\hline Question No. 1 & $2.69 \pm 1.21$ & $2.79 \pm 1.22$ & $p=0.001$ \\
\hline Question No. 2 & $2.57 \pm 1.27$ & $2.77 \pm 1.19$ & $p=0.001$ \\
\hline Question No. 3 & $2.81 \pm 1.29$ & $2.99 \pm 1.09$ & $p=0.002$ \\
\hline Question No. 4 & $2.98 \pm 1.93$ & $3.01 \pm 1.02$ & $p=0.001$ \\
\hline Question No. 5 & $3.01 \pm 1.22$ & $2.41 \pm 1.41$ & $p=0.03$ \\
\hline Question No. 6 & $2.32 \pm 1.12$ & $2.44 \pm 1.01$ & $p=0.04$ \\
\hline Question No. 7 & $2.51 \pm 1.41$ & $2.91 \pm 1.39$ & $p=0.001$ \\
\hline Question No. 8 & $2.69 \pm 1.19$ & $3.11 \pm 0.89$ & $p=0.001$ \\
\hline Question No.9 & $2.37 \pm 1.29$ & $1.72 \pm 1.41$ & $p=0.001$ \\
\hline Question No. 10 & $2.21 \pm 1.21$ & $3.31 \pm 1.01$ & $p=0.001$ \\
\hline Question No. 11 & $2.31 \pm 1.11$ & $2.41 \pm 1.01$ & $p=0.001$ \\
\hline
\end{tabular}

The Table no 4, presents the results of the study expressed as mean \pm SD, comparing the perceptions of male and female medical students. The results showed a significant difference between their perceptions regarding the present medical curriculum. The Figure No. 10: Showing the results.

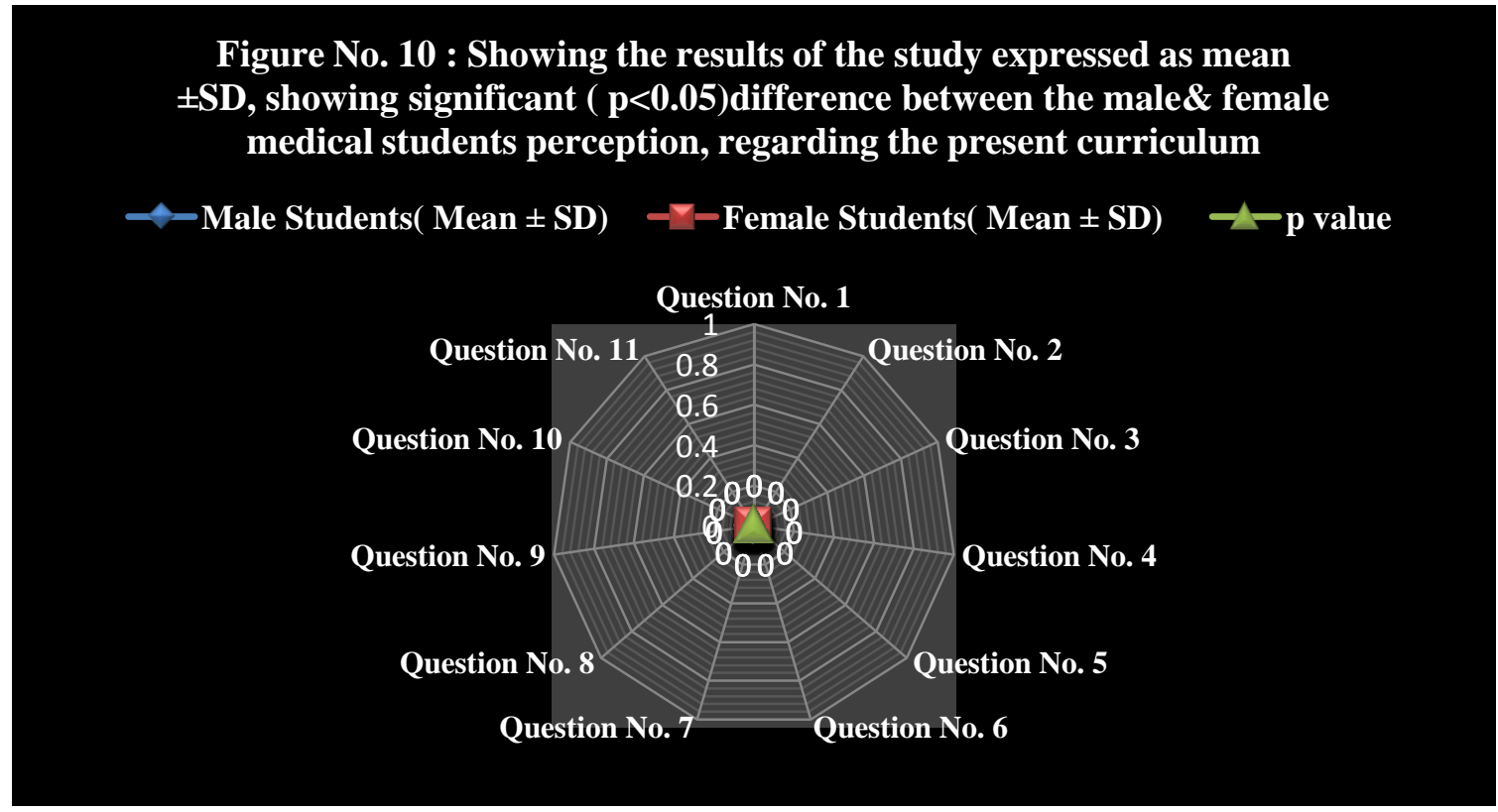

\section{DISCUSSION}

M.B.B.S curriculum is very vital and crucial for the medical students, the future doctors, where knowledge, skill, attitude developed. A well constructed curriculum can test higher order diagnostic thinking and application of knowledge. The medical curriculum should be designed so as to provide adequate opportunities to acquire independent learning skills.Medical education is changing rapidly, with more than half of the American schools being engaged in curricular reforms ${ }^{20,21,22}$.WHO also adopted newer concept in medical education such as problem based / oriented learning, integrated medical education, learnercentered educational activity ${ }^{6}$. Many modern medical institution have adapted Jerome Bruner's ${ }^{23,24}$ concept of the "spiral curriculum," and used it in their medical teaching. Also sometimes referred to as the spiral of learning ${ }^{14}$. The spiral curriculum is based upon an iterative revisiting of topics, subjects or themes throughout the course. A spiral curriculum is not simply the repetition of a topic taught. It requires also the deepening of it, with each successive encounter building on the previous one. Some medical institutions adopted integrated curriculum as, cognitive theories of learning suggest that an integrated approach to education may have important benefits for learning and retention because it facilitates contextual and applied learning and can promote development of the well organized knowledge structures that underlie effective clinical reasoning ${ }^{25,26}$. 
Lots of studies conducted on the curricular reform in the whole world ${ }^{12-16}$.It is the well constructed curriculum can fulfill the goal of medical education and need of curricular reform. For this feedback ofthe students perception regarding the present curriculum is essential and can help the planning. In this perspective this study was conducted in my institution among the final year medical students because they crossed a long journey in the medical education. Their perception regarding the present curriculum signifies a lot.

In this study eleven pointed questionnaires were distributed, validity and reliability of them tested by Cronbach Alpha. Alpha was developed by Lee Cronbach in 1951 to provide a measure of the internal consistency of a test or scale; it is expressed as a number between 0 and 1 . Internal consistency describes the extent to which all the items in a test measure the same concept or construct and hence it is connected to the inter-relatedness of the items within the test. Internal consistency should be determined before a test can be employed for research or examination purposes to ensure validity in addition to reliability ${ }^{27}$.

\section{REFERENCES}

[1]Prideaux D. ABC of learning and teaching in medicine curricular design. BMJ, 2003; 326: 268.

[2] Curriculum and syllabus. Available in: http://languagesoftheworld.info/morphology/the-plural-of-virus-

latinate-plurals-reconsidered.html

[3] Syllabus. Available in: http://www.usingenglish.com/forum/askteacher/51809-syllabus-vs-syllabi.html

[4] Stenhouse L. An introduction to curriculum research and development. London; Heinemann: 1975.

[5] Ludvigsson J. A curriculum should meet future demands. Med Teach 1999; 21: 127-128.

[6] World Health Organization. Doctors for Health.A WHO global strategy for changing medical education and medical practice for health for all. Geneva: World Health Organization; 1996.

[7] Enarson C and Burg FD. An overview of reform initiatives in medical education.1906 through 1992. Journal of the American Medical Association 1992: 268; 1141-1143.

[8] Slattery J.M and Carlson, J.F. Preparing an effective syllabus: current best practices. College Teaching, 2005;54 (4): 159-164.

[9] Anwar UI Haque. Medical Curriculum \& Teaching Strategies: Need for Constant Evaluation and Improvement. International Journal of Pathology; 2006; 4(2): 73-74.

[10] Davis MH, Harden RM: Planning and implementing an undergraduate medical curriculum: the lessons learned. Medical Teacher 2003, 25(6):596-608.

[11] Jones R, Higgs R, de Angelis C, Prideaux D: Changing face of medical curricula. Lancet 2001, 357:699-703.

[12] Irby DM, University of California San Francisco, School of Medicine, Association of American Medical Colleges. The Education of Medical Students: 10 Stories of Curriculum Change. New York: Milbank Memorial Fund 2000; 45-69.

[13] Anderson MB. A guide to the 130 reports in this snapshot supplement to Academic Medicine. Acad Med 2000;75 (9 Suppl):S10-S14.

[14] Kahn N, Davis A, Wilson M, Wartman S, Sherwood R, Nowalk A, Kahn R, Bazell C. The Interdisciplinary Generalist Curriculum (IGC) project: an overview of its experience and outcomes. Acad Med 2001 Apr;76 (4 Suppl):S9-S12.
There was limitation of this study as this study was conducted among one academic year, having small sample size, in only one institution. But majority of the students addressed their stress and tiredness, boring aspect of the present curriculum. And they believed that the present medical curriculum not a helpful curriculum to stimulate the research activities among the students.

In this study $91.52 \%$ male students and $87.81 \%$ of female students gave their favorable opinion regarding the change of the present medical curriculum.

\section{CONCLUSION}

Continuous quality improvement and innovations are essential in a medical education. More important are the studies of the students' perceptions because it is the students' perception and suggestion can improve the quality of the syllabus. Though there was limitation of the study but the majority of the final year medical students believed and agreed that there should be the change of the current medical curriculum.

[15] Muller J, Shore W, Martin P, Levine M, Harvey H, Kelly P, McCarty S, Szarek J, Veitia M. What did we learn about interdisciplinary collaboration in institutions? Acad Med 2001;76 (Suppl 4):S55-60.

[16] Nierenberg DW. The use of vertical integration groups to help define and update course /clerkship content. Acad Med 1998;73 (10):1068-71.

[17] Messick S. Validity of psychological assessment: Validation of inferences from persons' responses and performances as scientific inquiry into score meaning. Am Psychol. 1995; 50(9): 741-9.

[18] Likert Scale. Available in:

poincare.matf.bg.ac.rs/ kristina/topic-dane-likert.pdf

[19] Archives of Psychology. 1932.

Available in:

http://www.performancezoom.com/performanceszoom_fichiers/likert .gif

[20] Howe A, Campion P, Searle J, Smith H: A new perspective approaches to medical education at four new UK medical schools. British Medical Journal 2004, 329:327-331.

[21] Satterfield JM, Mittenss LS, Tervalon M, Adler N. Integrating the social and behavioral sciences, in an undergraduate medical curriculum: The UCSF essential core. Academic Medicine, 2004; 79(11): 6-15.

[22] El-Hazmi MA, Haque SM: Curriculum Evaluation: Status and Options. Med Educ 1985; 19: 48-53.

[23] Bruner J: The Process of EducationHarvard University Press, Cambridge, Massachusetts; 1960.

[24] Davis MH: OSCE: The Dundee experience. Medical Teacher, 2003, 25:255-261.

[25]Vidic B, Weitlauf HM. Horizontal and vertical integration of academic disciplines in the medical school curriculum. ClinAnat 2002;15:233-5.

[26]Regehr G, Norman G. Issues in cognitive psychology: implications for professional education. Acad Med; 1996;96:9881002.

[27] Cronbach LJ. Coefficient alpha and the internal structure of tests.Psychometrika.1951; 16:297-334. 